\title{
An open-label multicentre pilot study evaluating the pharmacokinetics (PK) of co-administered lopinavir (LPV) and nevirapine (NVP) in HIV+ adults LJ Else*1, TW Mahungu' ${ }^{2}$, Z Cuthbertson ${ }^{2}$, CJ Smith ${ }^{3}$, D Podlekareva ${ }^{4}$, P Hay ${ }^{5}$, UB Dragsted ${ }^{4}$, SH Khoo ${ }^{1}$, MA Johnson ${ }^{2}$, DJ Back ${ }^{1}$ and M Youle ${ }^{2}$
}

Address: ${ }^{1}$ Department of Pharamcology and Therapeutics, University of Liverpool, Liverpool, UK, ${ }^{2}$ Department of HIV Medicine, Royal Free NHS Trust, London, UK, ${ }^{3}$ Department of Primary Care and Population Sciences, Royal Free and UCL Medical School, London, UK, ${ }^{4}$ Copenhagen HIV Programme (CHIP), Copenhagen, Denmark and ${ }^{5}$ St George's Hospital, London, UK

* Corresponding author

from Ninth International Congress on Drug Therapy in HIV Infection

Glasgow, UK. 9-13 November 2008

Published: 10 November 2008

Journal of the International AIDS Society 2008, I I (SuppI I):P250 doi:I0.II86/I758-2652-I I-SI-P250

This abstract is available from: http://www.jiasociety.org/content/I I/SI/P250

(c) 2008 Else et al; licensee BioMed Central Ltd.

\section{Purpose of the study}

Co-administration of LPV/r SGC with NVP, an inducer of CYP3A, necessitates a LPV/r dose increase. The objectives of "The NRTI Sparing Study" were to evaluate the PK of coadministered LPV/r and NVP in HIV-infected subjects at week 4 and to assess any changes in these PK parameters at 48 weeks follow-up.

\section{Methods}

In this prospective, 48-week (wk), multicentre study, 40 patients (39 ART-naive) were recruited to receive LPV/r SGC (533/133 mg BID) plus NVP (200 mg BID) and undergo PK sampling ( $0-12 \mathrm{hr})$ at wk 4 and wk 48 . In one of the two participating centres, switches to the LPV/r tablet formulation (400/100 mg BID) were allowed between wk 4 and 48 , once HIV-RNA was $<50$ copies/ml. LPV concentrations were determined by HPLC-MS/MS and NVP concentrations via HPLC-UV. PK parameters were calculated via non-compartmental analysis and within-subject changes assessed by geometric mean ratios (GMR) with $95 \%$ confidence intervals $(95 \% \mathrm{CI})$.

\section{Summary of results}

Wk 4 PK data were available on 35 patients. Geometric mean (95\% CI) LPV AUC and C were 92012 ng.h $/ \mathrm{ml}$ (81237-104215) and $3979 \mathrm{ng} / \mathrm{ml}$ (3159-5011), respectively. For NVP these values were 62749 ng.h/ml (55621-
$70790)$ and $4594 \mathrm{ng} / \mathrm{ml}$ (4023-5246), respectively. At wk 24 , five individuals had HIV-RNA $>50$ copies $/ \mathrm{ml}$. Wk 4 PK data was available on $4 / 5$ of these patients, all of whom had LPV and NVP concentrations greater than the proposed trough concentration desirable in patients with wild-type HIV-1 (1000 and $3000 \mathrm{ng} / \mathrm{ml}$, respectively). Twenty-five patients also underwent wk 48 PK sampling; of these 10 remained on SGC, while 15 switched to the tablet formulation (400/100 mg BID). No significant intra-individual changes in PK were observed over $48 \mathrm{wks}$ for patients remaining on SGC ( $p>0.24)$. In those switching to the tablet, PK parameters were not significantly different $(p>0.68)$, although there was a trend towards lower LPV C at wk 48 (see Table 1).

\section{Conclusion}

This study explored an NRTI sparing strategy. We recognise that one limitation is that some patients were switched to the LPV/r tablet formulation. The issue of whether, if starting with this strategy, a dose of $400 / 100$ $\mathrm{mg}$ or $600 / 150 \mathrm{mg}$ tablet would be used, has not been addressed here. PK parameters at wk 4 and 48 did not differ significantly in patients receiving co-administered $\mathrm{LPV} / \mathrm{r}$ and NVP. However, there was a trend towards lower LPV C in patients who switched to LPV/r tablet. Therefore, there is a need for caution and a consideration for TDMguided dose adjustment depending on the population. 
Table I:

\begin{tabular}{|c|c|c|c|c|}
\hline PK [patients remaining on LPV/r SGC $(n=10)]$ & Wk 4 & Wk 48 & GMR $(95 \% \mathrm{Cl})$ & CV\% wk 4; wk 48 \\
\hline LPV AUC0-12, ng.h/ml & $10295 \mid(853 \mid 8,130692)$ & $91589(84050,101101)$ & $0.89(0.70,1.13)$ & $34 ; 15$ \\
\hline LPV Ctrough, ng/ml & $4848(36 \mid 5,7952)$ & $5230(4347,6794)$ & $1.08(0.67,1.75)$ & $60 ; 35$ \\
\hline LPV Cmax, ng/ml & $12307(10659,14663)$ & $11115(10209,12251)$ & $0.90(0.75,1.08)$ & $26 ; 15$ \\
\hline NVP AUCO-I2, ng.h/ml & $71850(67089,90850)$ & $68793(58059,86236)$ & $0.96(0.83,1.10)$ & $45 ; 33$ \\
\hline NVP Ctrough, ng/ml & $5254(4933,6676)$ & $4932(4032,6527)$ & $0.94(0.76,1.16)$ & $45 ; 40$ \\
\hline NVP Cmax, ng/ml & $6924(6440,8741)$ & $6830(5846,8385)$ & $0.99(0.85,1.15)$ & $46 ; 30$ \\
\hline PK [patients switching to LPV/r tablet $(n=15)$ ] & Wk 4 & Wk 48 & GMR $(95 \% \mathrm{Cl})$ & CV\% wk 4; wk 48 \\
\hline LPV AUC0-12, ng.h/ml & 77332 (6840I, 87428) & $67853(60277,85324)$ & $0.88(0.67,1.14)$ & $26 ; 34$ \\
\hline LPV Ctrough, ng/ml & $3 I 7 \mid(2355,427 I)$ & $2164(2013,3688)$ & $0.68(0.37,1.24)$ & $62 ; 58$ \\
\hline LPV Cmax, ng/ml & $9393(8619,10518)$ & $8706(7618,10846)$ & $0.93(0.76,1.12)$ & $20 ; 35$ \\
\hline NVP AUC0-I2, ng.h/ml & $55289(49589,64356)$ & $57231(50758,64528)$ & $1.04(0.88,1.21)$ & $26 ; 26$ \\
\hline NVP Ctrough, ng/ml & $3984(3842,4947)$ & $4063(3540,4665)$ & $1.02(0.86,1.21)$ & $28 ; 29$ \\
\hline NVP Cmax, ng/ml & $5447(4918,6251)$ & $5576(5004,6469)$ & $1.02(0.88,1.20)$ & $24 ; 25$ \\
\hline
\end{tabular}

Values given as geometric mean $(95 \% \mathrm{Cl}) ; \mathrm{CV} \%$ = coefficient of variation (\%).

Publish with Biomed Central and every scientist can read your work free of charge

"BioMed Central will be the most significant development for disseminating the results of biomedical research in our lifetime. "

Sir Paul Nurse, Cancer Research UK

Your research papers will be:

- available free of charge to the entire biomedical community

- peer reviewed and published immediately upon acceptance

- cited in PubMed and archived on PubMed Central

- yours - you keep the copyright

Submit your manuscript here:

http://www.biomedcentral.com/info/publishing_adv.asp 